\title{
Character Skills and Patience to Promote Resilience in Children - Education in Primary Schools After Pandemic
}

\section{Emanuela Guarcello}

University of Turin

\begin{abstract}
The proposal of the education of character skills in childhood has and still represents an authoritative experience within the educational landscape with particular regard to the school environment. If the proposal of character education has been so widely accepted to date, how can it be a valid support for the school even after the pandemic? In order to represent a valid support to all intents and purposes, should it maintain the traits that have distinguished it up to now or should it change in some respects? In particular, what skills should then be promoted by character education in schools after the pandemic? Starting from these problematic spaces and in order to work on a reconstruction of possible answers to the questions raised, the present contribution is articulated around three main reflexive nests: the education of character with particular regard to the proposal of character skills by James Josef Heckman; the relationship between conscientiousness (central to the discourses on character) and patience, an educational proposal centered on patience's skills that should be promoted through character education in schools, especially at primary level, after the pandemic.
\end{abstract}

Keywords: primary school, character, skills, conscientiousness, patience, resilience, waiting, indecision

\section{Introduction}

The proposal of the education of character skills in childhood has and still represents an authoritative experience within the educational landscape with particular regard to the school environment. Many have been the voices of scholars who have argued the importance of the formation of character as a manifestation par excellence of the person. In fact, character is understood as the central nucleus from which the person expresses their originality, decides and acts in the world by managing issues whether ordinary or extraordinary or complex in view of the good whether personal or communal.

If the proposal of character education has been so widely accepted to date, how can it be a valid support for the school even after the pandemic? In order to represent a valid support to all intents and purposes, should it maintain the traits that have distinguished it up to now or should it change in some respects? In particular, the skills that are recognized as constitutive to the central aspects of the character itself should be reviewed in the light of the pandemic experience that calls the school to its commitment to contribute to the promotion of resilience in children facing critical events, pandemic or not, that can cross their lives? What skills should then be promoted by character education in schools after the pandemic? 
Starting from these problematic spaces and in order to work on a reconstruction of possible answers to the questions raised, the present contribution is articulated around three main reflexive nests. The first thoughtful node, whose roots lie in a distant and authoritative past, is represented by the education of character with particular regard to interpretation that until now is within the theoretical framework of human capital in relation to the proposal of character skills by James Josef Heckman. The second reflexive node opens a focus on one of the dimensions that in the heckmanian perspective is constitutive of character, conscientiousness, subsequently relating it to a dimension currently not central to the discourses on character, patience. The third reflexive node argues a proposal centered on patience and related skills understood as central aspects that should be promoted through character education in schools, especially at primary level, after the pandemic.

\section{Character skills for school and society}

«One of education's principal functions is therefore that of fitting humanity to take control of its own development. It must enable all people without exception to take their destiny into their own hands so that they can contribute to the progress of society in which they live, funding development upon the responsible participation of individuals and communities» (Delors,1996, pp. 78-79).

The words of Jacques Delors, contained in the "Report to UNESCO of the International Commission on Education for the Twenty-first Century" highlight the obvious importance of the full realization of oneself and of one's own abilities as a condition of opportunity to participate in the "progress" of society. The society to which the Delors report refers sees the central focus of every process of change in the «capacity» of the person «to produce the new» (Rossi, 2009, p. 95) and therefore recognizes in "human capital" the source, as well as the condition of a continuous "strengthening" as a continuous process of humanization.

The very expression human capital sums up the idea of a wealth of skills that allow both individuals and society to invest in the future (Folloni \& Vittadini, 2010) ${ }^{1}$. Because of the importance of this asset of capacity in life, both personal as well as professional and social, many attempts have been made to clarify its forms and content. Among the most significant interpretations are that of James Joseph Heckman who, identifying human capital with skills, believes that they are not only in the cognitive area but rather in the area of personality (Gutman \& Schoon, 2013).

«Here lies the discovery that brings the theory of human capital to a new decisive stage. Human capital cannot be reduced to cognitive skills: [...] deep personality traits, desire-related aspects and socioemotional dimensions must also be considered.] deep personality traits, desire-related aspects and socioemotional dimensions must also be considered» (Vittadini, 2016, p. 13).

The American Society of Psychology has explained boundaries and profiles of these "traits" defining them "The Big Five" and detailing them through the O.C.E.A.N. acronym: Openness to experience, Conscientiousness, Extraversion, Agreeableness, Neuroticism. The Big Five are

1 The expression "Human Capital" rises a lot of reflections within pedagogical literature. "It is better to temper, then, the concept of "human capital", in order to render it, at the same time, more functional and meaningful with the concepts of "social capital", diffuse and ordinary practice of subsidiarity and social economy, validating the formative outcomes that, also and most of all, emerge from their intersection and from their overlaps" (Bertagna, 2012, pp. 36-37). 
conceived as general coordinates within which it is possible to state specific character skills, such as perseverance, self-control, trust, promptness, self-esteem, self-efficacy, resilience, availability, humbleness, tolerance of other people points of view, productive engagement in society.

It is within this construction that Heckman believes that these skills do not have to be defined "soft skills", "life skills" or "personality skills", but "character skills" (Kautz, Heckman, Diris, ter Weel \& Borghans, 2014, p. 13). The choice of Heckman is motivated by the need to precisely emphasize the unitary nature of skills. Character skills in fact «are not a list of qualities without any connection among them. Instead they are peculiar manifestations of a man's complex and fundamental aspect, that is his/her character» (Vittadini, 2016, p. 14). Therefore, character skills represent specific operational abilities that make manifest the «internal capabilities» which are the potential capacities of action that every person can and wants to pursue ${ }^{1}$.

The idea of character skills reconstructed by Heckman offers itself as an interesting theoretical-practical frame in relation to the deep "revolution" that today's world is living. In fact, since the eighties, the "paradigm of standardization" of Fordism has undergone a radical change. Following the kuhnian interpretation of paradigmatic dynamics, this change has contributed to a real «revolutionary transformation of vision» (Kuhn, 2012, p. 113) of such disruption and depth that it has started a fourth Industrial Revolution -Industry 4.0.

The fourth Industrial Revolution is characterized by its being an expression of the "paradigm of flexibility and innovation", connected in particular to the digitalization of operational activities and the remote control of production and flow of materials (WEF, 2016). It is precisely this digital transformation of work and above all of existence itself that makes skills, in particular character skills, an increasingly debated issue because it is increasingly recognized for its importance and, as a result, increasingly strategic in the formation of new generations. Skills, in fact, take on a crucial importance in the international training panorama, as they constitute that set of basic abilities through which it is possible to promote the widest skills that foster their own growth and the common world (Dyer, Gregersen \& Christensen, 2019; Costa, 2018; Bacigalupo, Kampylis, Punie \& Van de Brande, 2016).

\section{Starting from "yesterday": Character Education and its roots in the past}

The issue of character skills is not a new theme. It has in fact been the object of reflection dating back to classicism, repeated in all the successive epochs, to the present day. Reflection on character already finds in the works of Plato and Aristotle an important articulation: «It is true now, as it was in the days of Plato and Aristotle, that the character of a people is responsible for its social and political life, and that education is very important because it produces or modifies that character and, in this way, affects public interests» (Impara, 2002, p. 69).

This long tradition, which places the question of character at the heart of man's reflection, has found fertile ground in the pedagogical field. It is particularly moral education that has offered an authoritative framework within which the idea of character education has been deepened. The voices of Friedrich Wilhelm Förster and Eduard Spranger are significant expressions of this. Between the 19th and 20th centuries, they worked to define an implication between the

1 Based on Giorgio Vittadini's analysis, character skills do not arise as an alternative or in opposition to the capabilities approach (Heckman \& Corbin, 2016, pp. 342-359; Nussbaum, 2011, p. 30; Sen, 2009; Vittadini, 2016). 
values of character and education (Förster, 1970, 1912; Spranger, 1964, 1960). In this perspective, education represents a path through which man shows character by putting himself to the test in implementing an existence of meaning and value. This implementation can then take the path of obedience, according to Förster (Förster, 1970, p. 233) and of "inner normativity" according to Spranger (Spranger, 2000, p. 24).

Despite the blows that the idea of character has suffered since the 1920s, at the hands of the studies of "masters of suspicion» and anti-authoritarian theories ${ }^{1}$, the implication between values, character and education has survived and maintained its own significance. This was also possible thanks to speculations such as those of Emmanuel Mounier who saw a manifestation par excellence in the character of the person understood as «a lived activity of self-creation, communication and participation» (Mounier, 1990, p. 8).

A particular area in which the education of character has immediately found a privileged educational space is the school. In fact, the experiences are many of character education in the school context, but among them the "programs" of character education have taken on a particular significance (Character Education Movement) that, since the twenties of the last century, have spread to the United States ${ }^{2}$. Within the framework of the "Movement of Character Education", the educational focus is in particular on the promotion of the ability to self-regulate behaviour and judgment, intended in particular as an attitude to take morally correct action. It is precisely the focus on the development of moral capacities that constitutes the pivot around which the goals of «good character» (Lickona, 1991, p. 50; Lickona, 1983) education are articulated. Thomas Lickona, a well-known exponent of the "Movement of Character Education", clarifies the meaning on the basis of which this "good character" is intended. It «consists of knowing the good, desiring the good, and doing the good - habits of the mind, habits of the heart, and habits of action» (Lickona, 1991, p. 51).

\section{Until today: character skills and conscientiousness}

It is precisely in this ethical key that it is possible to read Heckman's reflection on the importance of a school that not only works for the intellectual empowerment of children, but also for the promotion of character skills that make those same children "ethically reliable":

«In addition to being an established economist, Heckman has strong interests for the future of the young generations convinced that without adequate education there will be no future either for them or for the communities in which they live. The education that Heckman promotes is not, however, the prevailing one based on strong doses of precocious cognitive exercises and a focus mainly on mastery of skills. According to the Chicago scholar, the educational challenge is won or lost to the extent that individuals are provided with character skills such as to make people not only intellectually prepared, but above all ethically reliable: people who have their own value set consisting of five main qualities: consistency in commitment, friendliness, conscientiousness, emotional stability, positive vision of the experience (the so-called Big Five)» (Chiosso, 2018, p. 186).

\footnotetext{
1 In particular, with "masters of suspicion" we refer to Friedrich Nietzsche, Karl Marx and Sigmund Freud and in relation to anti-authoritarian studies we refer in particular to the works of Max Horkheimer, Theodor Wilhelm Adorno and Herbert Marcuse.

2 In fact, following the drafting of the "Aspen Declaration on Character Education" in 1992, the international association "Character Education Partnership" was founded through which the guidelines for character education in schools have been defined and partnership projects have been launched in schools (Power, Nuzzi, Narvaez, Lapsley \& Hunt, 2008, pp. 23-25).
} 
Based on Heckman's analysis, among these five main qualities the most promising for success in studies, work and daily life is conscientiousness. Indeed, conscientiousness «predicts the number of years of study with the same force as intelligence assessments ». In addition, it «has been linked, in the workplace, to the level of performance and salary development». Finally, it «is a more powerful predictive factor of longevity than all the other big factors» (Heckman \& Kautz, 2016, pp. 112-115).

The conscientiousness is understood by Heckman as scrupulousness, reliability and selfdiscipline, as the ability to pursue a goal with precision. People with this personality trait are reliable and meticulous people, who work hard to achieve as excellent a result as possible. They are used to examining all the possibilities before acting. They have a strong sense of duty and obligation (Shum, Gatling, Book \& Bay, 2019). Ron Sun, reflecting on Heckman's noncognitive skills, links «conscientiousness» to «Patience, and trustworthiness» (McArdle \& Willis, 2012, p. 362).

In Heckman's speech, in fact, conscientiousness calls for patience because both express the ability to commit accurately and feel responsible for the excellent success of their work. The «skills» that both conscientiousness and patience make manifest are «"grit", perseverance, ability to defer gratification, control of one's own impulses, commitment, ambition and work ethic» (Heckman \& Kautz, 2016, pp. 98-99). These are skills that place a particular emphasis on the work being carefully and diligently carried out.

In particular as regards patience, it is in effect often identified with the ability to defer gratification and to delay the result itself: "Patience" is a recommended means to obtain academic, social, and economic success» (Barragan-Jason \& Cauchoix, 2019, on line publication). Patience is grasped in its ability to tolerate delay (Barragan-Jason. Atance, Kopp \& Hopfensitz, 2018), renouncing immediate but reduced "results", in view of results that are more distant in time but quantitatively greater. With regard to conscientiousness (in study, in work and in daily life), it also implies a deferral of gratification in order to complete one's task with the greatest possible precision and completeness. In fact, conscientiousness, in the first place, directs the person to declare his work completed only when the commitment was such as to have led to the realization of a work done in the best possible way. So conscientiousness, secondly, directs the person to tolerate a non-trivial amount of fatigue in view of achieving a success that is further in time and that is perceived as important and meaningful for themselves.

If conscientiousness, with its capacity for self-control and deferment, has up to now assumed the central role in the discourse on character skills, It is precisely this engagement with patience that must be brought to the fore in the reflection on the most promising skills in the post-pandemic school. Patience, in fact, while placing itself in continuity with conscientiousness, is not really its synonym but has its own characters that can make it one of the most significant character skills both to "resist" in the pandemic and to re-build after the pandemic.

\section{From "tomorrow": character, patience and ability to resist in adversity}

The pandemic has and will require not only the ability to defer gratification, meticulousness and perseverance in meeting goals. Both the current one and those that could happen in the 
future, has and will, above all, deem necessary the ability to resist in those particular cases when one is "crushed" from «adversity» ${ }^{1}$ in which one is forced to stay for a prolonged period.

This specific ability to resist represents the first and most recognizable meaning of patience, as clearly emerges from the intertwining of the Greek verbal forms that translate the word

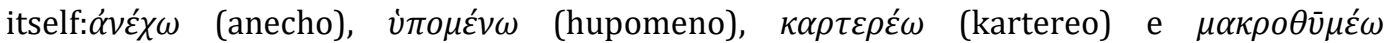
(makrothymeo) (Bommarito, 2014; Guarcello, 2019; Pianalto, 2016).

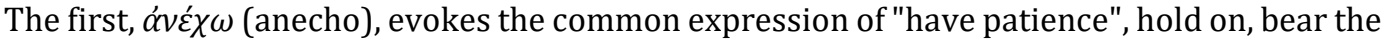
weight of the conditions that require presence. It expresses the concepts of keeping your head up and of keeping on top of oneself which, although interesting in relation to the scope and strength of the endurance itself (not to let oneself be put down), can imply an idea of immobility. Steadiness certainly implies a condition of stability, firmness, rootedness, but not necessarily static and devoid of concrete objectives.

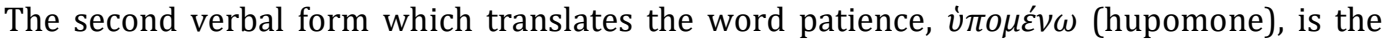
ability to «hold position», not retreat and hold the momentum (Tagliapietra, 2016, p. 15). It is a term that imposes itself in parallel to the spread of stoicism and recalls the deeds of the Greek phalanx warriors, who held their position firmly to save others, protecting with spear and shield the body of their partner. It is a state that, while proposing the condition of endurance and steadfastness, implies a push towards active resistance, aimed at an objective with impetus, even while restrained.

The third verbal form that translates the word patience, $\kappa \alpha \rho \tau \varepsilon \dot{\varepsilon} \eta \sigma \iota$ (karteresis), expresses

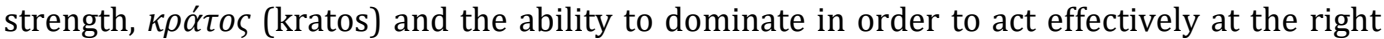
time $^{2}$. It is represented by the Homeric heroes Hector and Ulysses in relation to their ability to wait and defend while in battle, and then to understand the time and the most appropriate way to overcome the opponent.

Precisely on the basis of these meanings, patience cannot be identified and exhausted within the boundaries of perseverance and constancy. Constancy and perseverance, with different forms and modes, intervene in complicated but manageable circumstances, programmable and winnable with an assiduous, precise and continuous behaviour. The circumstances within which patience "works" are complex because unlike what happens in perseverance and constancy, they imply the endurance of what cannot be explained rationally, which is difficult and for which there is no certainty of a positive outcome.

Constancy and perseverance, as well as tenacity, persistence and permanence, intervene in patience but do not exhaust «the semantic area of "patience"» (Caramore, 2014, p. 47) are not synonymous and do not represent the essence. In fact, being patient is best expressed by two dimensions that constitute it: firmness and fortitude. Firmness is one who welcomes difficulty, failure, darkness with an attitude of firm surrender, the one who courageously remains in view of transforming this difficulty. Fortitude is one who expresses strength, the cardinal virtue proper to one who faces formidable difficulties with ardour, not yielding definitively to fear and temptation to escape from dangers: «Patience [...] is the way of fortitude. [...] But no one

1 Gregory the Great, one of the Fathers of the Church, believed that the virtue of patience cannot be exercised in prosperity. The true patient is the one who is crushed by adversity and yet does not deviate from the righteousness of his hope (Gregorio Magno, 1965, p. 337).

2 / «To have patience means to be able to hold back and then to strike, to master the strength and then to exercise it» (Tagliapietra, 2016, p. 15). 
has the right to demand the capitulation of another. [...] For this who is patient is forbearing» (Natoli, 1996, pp. 104-106).

Forbearance leads back to the last Greek language form that translates the word patience: $\mu \alpha \kappa \rho о \theta \bar{v} \mu i \alpha$ (makrothymia). Makrothymia is a quality attributed to God and manifested by him through the ability to tolerate the mistakes of men and to wait for their change in the desired direction ${ }^{1}$. The makrothymia, meaning a slowness to anger and literally the "length of mind", is involved in the staying of patience because it expresses the intention to hold the impetus of anger against the other, understanding it and somehow accepting it for what it is, waiting for his transformation.

Thus outlined, in the interweaving of the dimensions previously expressed, the capacity of patience finds its core in resisting. Nothing in constancy, perseverance, tenacity, endurance shows unequivocally the dimension of resisting in the confrontation with what is looming externally: the impact, the weight, the clash, the rip. If ${ }^{2}$ patience could speak in fact he would say "we have the duty to resist: resist here and wherever possible, against everything that humiliates, subjugates and separates. To transmit what elevates, liberates and unites [...]. A freedom to be conquered against all fatalism» (Meirieu, 2007, p. 120).

As a central aspect of patience, the ability to resist is not innate, casual or there by chance. Patience can be considered a trait of character, an aspect of personality and, just as such, it is not purely instinctual but can and must be educated. Patience, and therefore the ability to resist in adverse situations, matures in relational and educational interaction and therefore since primary school, finds a privileged, meaningful and effective field of exercise and promotion. The more the school is able to work early on the dimension of patience, the more children will be able to develop a solid capacity to stay in adversity, managing to rework the meaning of what they experience and making it an opportunity that contributes to the positive construction of its future.

\section{For the post-pandemic school: educating patience in order to promote resilience}

According to Albert Mehrabian's classification, patience and its ability to resist can be exercised by children in three different forms: long-term patience (e.g. illness), short-term patience (e.g. driving in traffic) and interpersonal patience (tolerance) (Mehrabian, 2012, pp. 263-280). These three forms represent life experiences with which children deal commonly and frequently. At the same time, these three forms also represent three different aspects with which children have had to deal in the experience of the Covid-19 pandemic.

In fact, the pandemic has confronted children with the need to exercise their ability to resist in the long term at least in relation to three different areas. Firstly, in relation to the restrictive measures imposed for the health control of the pandemic; secondly, in relation to the emotional discomfort associated with prolonged isolation and the alert status of possible contamination; thirdly, in relation to the most unfortunate cases of direct or indirect illness experienced by family members, close relatives or reference adults.

In addition, the pandemic has confronted children with the need to exercise their ability to resist in the short term in relation to the tasks that have been requested daily by their schools

1 Makrothymia expresses the image of patience proper to biblical language. It is understood as God's quality of delaying wrath, leaving room for the slow maturation of a mercy that surpasses the immediacy of judgment and guilt. 
(distance learning), the needs of home life (routines of life) and social distancing at the time of resuming contacts with peers and with their social networks of reference.

Finally, the pandemic confronted children with the need to exercise their ability to resist in an interpersonal sense, that is, not to give in to the temptation to consider the other (the potentially "infected") as a person to demonize, to exclude or to attack.

The children had to deal with these three forms of patience without having worked in advance to improve the capacity to resist, which is necessary to face the difficulties and adversities that each of these forms involved. Patience, in fact, although it is a concept that has traversed humanity's intense history from antiquity until today, has not found a structured and systematic place in our primary schools. It must certainly be made clear that work to promote and strengthen the capacity to resist does not, of course, imply any guarantee that children will not encounter difficulties in managing exceptional moments, such as pandemic crises. However, there is no doubt that constant and early work to promote and strengthen the ability to resist could help the child to develop the resilience necessary to assimilate the shock wave of traumatic events, such as pandemic (Jiao et. Al., 2020, on line publication, italics is mine), to survive and to build experiences as significantly as possible even within adversity. In fact, a large part of current studies (Cheema-Fox, La Perla, Serafeim \& Wang, 2020; Wu, Connors \& Everly, 2020) see resilience's strategies as a central aspect for the most constructive management of the Covid-19 pandemic experience by both children and adults:

«(a) communication (clear information, emotional sharing, collaborative problem-solving, dyadic and family coping), (b) organization (adaptability [...]), and (c) belief systems (meaning-making, hope, and spirituality). These processes are purported to be disrupted or altered [...] in the context of the pandemic. They can also serve as sources of resilience» (Pime, Wade \& Browne, 2020, p. 4, italics is mine).

This is a resilience which finds patience (and "positive waiting") to be a premise and a necessary starting point in the ability to resist.

\section{The skills of patience and resilience}

Not being able to give an account here of the different capacities and skills underlying the dimension of patience, we limit ourselves to briefly highlighting two different skills that can be a solid starting point to consolidate a resilient attitude in the child. These skills are on the one hand a clear condition and expression of the ability to resist. On the other hand, they are skills which today are unfortunately largely lacking in the training of the child and neglected if not opposed by society itself, on the basis of its increasingly "unbridled" needs for efficiency. It is the skill of waiting and the skill of indecision.

The skill of waiting is one of the most recalled and studied dimensions in respect to patience. In patience the waiting is conceived mainly as the ability to resist in view of the possible fruits (in professional, financial, daily life) that you can get thanks to the waiting itself: «high I-Q populations are more patient and more risk averse than low I-Q populations. The correlation between Patience and intelligence corroborates previous results based on micro data. Intelligent people tend to be patient because they have long time Horizons» (Potrafke, 2019, pp. 116-120; Güss, Hauth, Wiltsch, Carbon, Chütz \& Wanninger, 2018).

In patience waiting is also conceived as "ability to tolerate a delay" not only in relation to waiting for a reward but also as "pure waiting» without precise perspectives of advantage (Barragan, Atance, Kopp \& Hopfensitz, 2018, pp. 14-30). So, the skill of waiting in patience is the ability to resist even without the clear prospect of a result but still developing the ability 
to live the moments of waiting in a constructive way, as experiences that are part of human everyday life and can be lived not only in a serene way but also in a fruitful way. This way of living the wait, of which the "marshmallows" experiments represent interesting experiences of research and reflection (Watts, Duncan \& Quan, 2018), needs a job aimed at exercising and promoting in children two specific strategies. The strategy of waiting by 'shifting attention' (Vigani, 2017, pp. 327-340; Duckworth, Gendler \& Gross, 2014, p. 208) and the strategy of waiting without emergency (Pianalto, 2016, pp. 81-100).

Waiting by dislocating attention involves the ability to resist a first temptation. In fact, it means knowing how to look at waiting by focusing attention on the possible outcome without being definitively distracted by the frustrations and inconveniences of waiting. The waiting aspect of patience is not without irritation or anger, as one would like in a perspective in which patience is emptied of all temptation. If waiting were an expectation without pathos it would not be waiting in patience. If the waiting were a waiting with pathos that was not yet caught or considered, it would be unawareness, denial or removal.

Waiting without emergency involves the ability to resist a second temptation: the temptation of urgency. The urgency hastens the outcome, does not wait for its time, it pursues it and in doing so it jeopardizes the success of the experience that is being lived. The urgency not only runs the risk of rushing the outcome, but also gives rise to anticipating and widening anxieties and concerns with regard to the concreteness of the problem that may arise or is already looming. The urgency in fact limits or deprives the person of sufficient lucidity to reflect on the experience he is experiencing thus preparing the necessary ground for an effective and significant problem solving.

The question of problem-solving leads to the second skill necessary to exercise the ability to resist: the skill of indecision. The skill of indecision is much less referred to in the studies on patience but has an immediate and clear connection with it. Indecision is involved with patience because it is the necessary prerequisite for decision-making. In fact, there are many studies that see in patience a self-control and a decision-making ability. Salman Akhtar believes that patience is the ability to orient oneself towards a goal by renouncing magical thinking and learning to endure ambivalence (Akhtar, 2018) which very often characterizes situations where a decision has to be made.

In particular, in relation to the ability of self-control and decision-making the theme of intertemporal choice is often called upon. Patience, in assessing the different opportunities, comparing their scope not only at a synchronic level but also at a diachronic level, is able to tolerate the time taken in the evaluation process and to decide on the basis of the subjectively perceived advantages (Mischel, Ayduk, Berman, Casey, Gotlib, Jonides \& Shoda, 2010; Doebel \& Munakata, 2018). These studies are basically in agreement in that they indicate patience as a dimension necessary to take a genuine, coherent and effective decision, aimed at objectives of interest with the ability to approach them. Patience gives the decision authenticity and effectiveness precisely because it brings the decision to maturity slowly while passing through a preliminary stage of indecision. Indecision, so opposed by the pressing rhythms and the performance approach of today's society, is in fact precious every time you are in a problematic situation, dilemmatic and difficult to decide.

With reference to the studies of Nicoletta Cavazza and Fabrizio Butera on ambivalence, it is possible to argue that "above all" where there are conflicting positions on the same object, both positive and negative, not only can the decision be made but can even be of better quality. 
As a result of the collection and analysis of more data, the decision will be more informed, relevant and responsive to one's own personality and interests. The multiplicity of data, while on the one hand increasing the perception of ambivalence and contradiction, on the other hand allows therefore to have a wide repertoire of reflections in order to come to a well-founded decision. There are not a few studies on the virtues of indecision and on the particular sensitivity possessed by the person who knows how to grasp the nuances and polarities of reality and, precisely for this reason, knows how to decide with appropriateness and soundness.

An example on which the authors reflect is chocolate. It is a not uncommon experience to feed a certain indecision between the love for chocolate and the concern for subsequent weight gain. This is therefore a situation of ambivalence: hatred and love coexist with chocolate. According to the authors this ambivalence does not prevent people from eating chocolate on some occasions and from abstaining on others, on the basis of what is considered appropriate (Cavazza \& Butera, 2008, pp. 1-15; Pillaud \& Cavazza, 2013, pp. 1139-1151).

Mario Mikulincer argues that this skill of indecision is not only present in adulthood, but that on the contrary it can be exercised already in children of 4-5 years. The child is able to perceive and understand the ambivalence of reality and people, so much so that for example they know how to connect negative feelings even to what they love. This ability is structured in an increasingly wide and complex way until reaching adulthood, when they are able to resist in a pre-decision situation in order to consider different possibilities before choosing (Boyatzis, 1982; Mikulicer \& Shaver, 2007).

The ability to resist in indecision, in order to lay the foundations of a well-founded and coherent decision, with respect to the initial problematic situation, is crucial in order to manage critical pandemic situations as constructively as possible. In fact, the child learns to resist in the difficult and uncomfortable ambivalences of reality, to become aware of them and to tolerate them. In addition, the child learns to manage experiences that contain both positive and negative aspects, which involve both feelings of pleasure and sorrow at the same time. Finally, the child learns to decide by evaluating the reality for the different nuances that it presents and tolerating the uncertainties derived from the number and contradiction of the variables in play. A child who has been accompanied to exercise this skill of indecision may more likely become an adult able to exercise making complex decisions in the face of enigmatic and ambivalent situations, characteristic of the crisis phases such as caused by pandemics, with which we may still be confronted.

Both skills of waiting and indecision promote a meta-competence which is what John Dewey defined as «incubation»:

Many persons having a complicated practical question to decide, find it advisable to sleep on the matter. Often, they awake in the morning to find that, while they were sleeping, things have wonderfully straightened themselves out. A subtle process of incubation has resulted in hatching a decision and a plan. But this bringing forth of inventions, solutions, and discoveries, rarely occurs except to a mind that has previously steeped itself consciously in material relating to its questions, has returned several matters off and over, weighed pros and cons. Incubation, in short, is one phase of a rhythmic process (Dewey, 1986, p. 345).

Patience and its capacity to resist act by postponing the action to understand in depth how it may impact on the future of oneself and others. At the same time, however, one does not 
necessarily act with a lack of readiness and excessive slowness. Furthermore, even in cases where, due to urgency, a prompt and immediate response is needed, this same response either follows indicatively pre-determined "protocols" or raises a question at least following the decision itself ("Having acted so quickly under pressing circumstances, were the decisions taken the most appropriate?"). Therefore in these cases the incubation capacity will be used not in relation to the "to-do", but in relation to the "already-done" so that it can be revised, integrated or corrected also for the benefit of the management of similar situations that might happen in the future.

Precisely for this reason patience promotes a capacity that, in times of Covid-19, rehabilitates the concept in its incubation and elevates it to a refined capacity for decision, action and critical review, all of which are promising for the management and improvement of the crisis situation in which you are living.

\section{Conclusion - Patience, discrimination and judgment: for a new school in a renewed society}

Starting from the reconstructed frame, it can be argued that the proposal of character education could be a valid support for schools, especially after the pandemic. Moreover, and above all, it can be a valid support if the skills such as conscientiousness, which are recognized as constitutive to the central aspects of character itself, are reviewed in the light of the pandemic experience. Indeed, the pandemic experience calls the school to its commitment to contribute to the promotion of resilience in children facing critical events, pandemic or not, which may cross their lives.

Consequently, skills that should then be promoted by character education are, in particular, the "skills of patience", more precisely those of "waiting" and "indecision". These are skills that enable children to increase their capacity to resist in moments of adversity, reflecting on the sense and problematic aspects of experience. On the basis of this resistance and reflection, children can identify the possible choices and strategies to cope with the crisis phases they are living.

It has always been the case, but even more so after the Covid-19 pandemic, that one of the main meanings of education in school should be to make humanity able to "reason about reality" even in the face of the shocking facts that it will unfortunately continue to reserve for us. Reasoning means giving ourselves time to know, and then on the basis of this knowledge to distinguish; finally, being able to judge reality by facing its adversities and contradictions to take a personal, consistent and well-founded position.

An education at school that commits itself, once again, to promoting a lucid capacity of judgment even in times of greatest adversity needs the patience, resistance and resilience necessary to know not only how to survive but above all how to build within the crisis. An education at school that promotes a clear judgment even in moments of greatest adversity is the only thing that today, after the pandemic, can safeguard and promote human capital. A human capital that knows not only how to develop unceasingly, but above all how to protect its own survival and to work for the construction of a new common world capable of being, finally, on a human scale.

«Patience, nourished by interest and hope, helps to explore the human story in its complexity. Thinking about reality is in fact having the patience to make a concrete comparison with it. First of all - as a well-known economist wrote - "to try to understand means for everyone to 
devote more time and more attention to the shocking facts that take place before our eyes". Instead people are in a hurry and rely on some simplified or publicised formula. Nowadays it is more necessary to taste than to know. Thinking about reality means learning to distinguish. Yes, distinguishing is fundamental, to avoid creating monsters or ghosts in the laboratory of our thoughts, adding into the same category different manifestations or expressions» (Riccardi, 2006, pp. 126-130).

\section{References}

[1] Akhtar, S. (2018). Silent Virtues. Patience, Curiosity, Privacy, Intimacy, Humility, and Dignity. London: Routledge.

[2] Almlund, M., Duckworth, A.L., Heckman, J.J., \& Kautz, T.D. (2011). Personality, Psychology and Economics. In E.A. Hanushek, S. Machin, L. Woessmann, Handbook of the Economics of Education. Vol. 4 (pp. 1-181). Amsterdam: Elsevier.

[3] Bacigalupo, M., Kampylis, P., Punie, Y., \& Van de Brande, G. (2016). EntreComp: The entrepreneur-ship competence framework. Luxembourg: Publication Office of the European Union.

[4] Barragan, J.G., Atance, C., Koppi C., \& Hopfensitz, A. (2018). Two facets of patience in young children: Waiting with and without an explicit reward. Journal of experimental Child psychology, 171, 14-30.

[5] Barragan-Jason, J., \& Cauchoix, M. (2019). Commentary on Revisiting the Marshmallow Test: A Conceptual Replication Investigating Links Between Early Delay of Gratification and Later Outcomes. Frontiers in Psychology, 9. Retrieved June 19, 2020, from https://www.ncbi.nlm.nih.gov/pmc/articles/PMC6335313/.

[6] Bertagna, G. (2012). Oltre la teoria del "capitale umano". In Bertagna G. (Ed.). Fare laboratorio. Scenari culturali ed esperienze di ricerca nelle scuole del secondo ciclo (pp. 32-129). Brescia: La Scuola.

[7] Bommarito, N. (2014). Patience and Perspective. Philosophy East and West, 64, 2, 269-286.

[8] Caramore, G. (2014). Pazienza. Bologna: Il Mulino.

[9] Cavazza, N., \& Butera, F. (2008). Bending without breaking: examining the role of attitudinal ambivalence in resisting persuasive communication. European Journal of Social psychology, $38,1,1-15$.

[10] Cheema-Fox, A., La Perla, B., Serafeim G. \& Wang H. (2020). Corporate Resilience and Response During COVID-19. Harvard Business School. Working Paper 20-108. Retrived June 14, 2020 from https://www.hbs.edu/faculty/Publication\%20Files/20-108_3a13a174-df28-474abb48-51d63c92fcfc.pdf.

[11] Costa, M. (2018). Industry 4.0: La tras-formazione dell'agire lavorativo. In P. Federighi (Ed.). Educazione in età adulta. Ricerche, politiche, luoghi e professioni (pp. 203-209). Firenze: Firenze University Press.

[12] Delors, J. (Ed.) (1996). Learning: The Treasure Within. Report to UNESCO of the International Commission on Education for the Twenty-first Century. Paris: UNESCO Publishing.

[13] Dewey, J. (1986). The Later Works, 1925 - 1953. Volume 8: 1933. Essay and How We Think, Revised Edition. Carbondale: Southern Illinois University Press.

[14] Doebel, S., \& Munakata, Y. (2018). Group influences on engaging self-control: children delay gratification and value it more when their in-group delays and their out-group doesn't. Psychology Science, 5, 29, 738-48.

[15] Duckworth, A.L., Gendler, S.T. \& Gross, J.J. (2014). Self-Control in School-Age Children. Educational Psychologist, 49, 3, 199-217.

[16] Dyer, J., Gregersen, H., \& Christensen, C.M. (2019). The Innovator's DNA: Mastering the Five Skills of Disruptive Innovators. Boston-Massachusetts: Harvard Business Review Press.

[17] Folloni, G., \& Vittadini, G. (2010). Human Capital Measurement: A Survey. Journal of Economic Surveys, 24, 2, 248-279.

[18] Förster, F.W. (1912). L'educazione Civica dei Giovani e degli Adulti. Torino: Nazionale. 
[19] Förster, F.W. (1970). Scuola e carattere. Contributo alla pedagogia dell'obbedienza e alla riforma della disciplina scolastica. Brescia: La Scuola.

[20] Gregorio Magno (1965). Moralia I (Passi scelti). Ancona: Paoline.

[21] Guarcello, E. (2019). Le azioni della pazienza. Impegnare, esplorare, osare. Roma: Studium.

[22] Güss, C.D., Hauth, D., Wiltsch, F., Carbon, C.C., Schütz, A., \& Wanninger, K. (2018). Patience in Everyday Life: Three Field Studies in France, Germany, and Romania. Journal of Cross-Cultural psychology, 3, 49, $355-380$.

[23] Gutman, L.M., \& Schoon, I. (2013). The Impact of Non-Cognitive Skills on Outcomes for Young People. London: Education Endowment Foundation.

[24] Heckman, J.J., \& Corbin, C.0. (2016). Capabilities and Skills. Journal of Human Development and Capabilities, 17, 3, 342-359.

[25] Impara, P. (2002). Platone filosofo dell'educazione. Roma: Armando.

[26] Jiao, W. Y., Wang, L. N., Liu, J., Fang, S. F., Jiao, F. Y., Pettoello-Mantovani, M., \& Somekh, E. (2020). Behavioral and Emotional Disorders in Children during the COVID-19 Epidemic. The Journal of pediatrics, 221, 264-266.

[27] Kautz, T., Heckman, J.J., Diris, R., ter Weel, B. \& Borghans L. (2014), Fostering and Measuring Skills: Improving Cognitive and Non-Cognitive Skills to Promote Lifetime Success. NBER Working Paper n. 20749. Cambridge-MA: National Bureau of Economic Research.

[28] Kuhn, T.S. (2012). The Structure of Scientific Revolutions: 50th Anniversary Edition. ChicagoLondon: The University Chicago Press.

[29] Lickona, T. (1983). Raising Good Children. Helping your child through the stages of moral development. New York: Bantam Books.

[30] Lickona, T. (1991). Educating for Character: How Our Schools Can Teach Respect and Responsibility. New York: Bantam Books.

[31] McArdle, J.J., \& Willis, R.J. (2012). Cognitive Aging and Human Capital. In R. Sun (Ed.), Grounding Social Sciences in Cognitive Sciences (pp. 351-384). Massachusetts: MIT.

[32] Mehrabian, A. (1999). Manual for the Revised Achieving Tendency (MACH) and Disciplined Goal Orientation (CGO) Scales. Alta Mesa-California: Monterey.

[33] Meirieu, P. (2013). Pedagogia: il dovere di resistere. Foggia: Edizioni del Rosone.

[34] Mischel, W., AyduK, O., Berman, M.G., Casey, B.J., Gotlib, I.H., Jonides, J., \& Shoda, Y. (2010). 'Willpower' over the life span: Decomposing self-regulation. Social Cognitive and Affective neuroscience, 6, 252-256.

[35] Mounier, E. (1990). Trattato del carattere. Cinisello Balsamo: Paoline.

[36] Natoli, S. (1996). Dizionario dei vizi e delle virtù. Milano: Feltrinelli.

[37] Natoli, S. (2014). Perseveranza. Bologna: Il Mulino.

[38] Nussbaum, M.C. (2011). Creating capabilities. Cambridge-Massachussetts: The Belknap Press of Harvard University Press.

[39] Pianalto, M. (2016). On patience: Reclaming a Foundational Virtue. London: Lexington Books.

[40] Pillaud, V., Cavazza, N., \& Butera, F. (2013). The Social Value of Being Ambivalent: SelfPresentational Concerns in the Expression of Attitudinal Ambivalence. Personality and Social psychology Bulletin, 39, 9, 1139-1151.

[41] Potrafke, N. (2019). Risk aversion, patience and intelligence: Evidence based on macro data. Economics Letters, 178, 116-120.

[42] Power, F.C., Nuzzi, R.J., Narvaez, D., Lapsley, D.K., \& Hunt, T.C. (Eds.) (2008). Moral Education. A Handbook. Volume One: A-L. Westport-Connecticut: Praeger.

[43] Prime, H., Wade, M., \& Browne, D. T. (2020). Risk and Resilience in Family Well-Being During the COVID-19 Pandemic. American Psychologist. Advance online publication. Retrieved June 10, 2020 from http://dx.doi.org/10.1037/amp0000660.

[44] Riccardi, A. (2006). Convivere. Roma-Bari: Laterza.

[45] Rossi, B. (2009). Educare alla creatività. Formazione, innovazione, lavoro. Roma-Bari: Laterza.

[46] Schnitker, S.A. (2012). An examination of patience and well-being. The Journal of positive psychology: dedicated to furthering research and promoting good practice, 4, 7, 263-280.

[47] Sen, A. (2009). The Idea of Justice. London: Allen Lane. 
[48] Shum, C., Gatling, A., Book, L., \& Bay, B. (2019). The Moderating Roles of Follower Conscientiousness and Agreeableness on the Relationship Between Peer Transparency and Follower Transparency. Journal of Business Ethics,154, 483-495.

[49] Spranger, E. (1960). Ambiente e cultura: lo spirito caratteristico della scuola di tutti. Roma: Armando.

[50] Spranger, E. (1964). Educazione e diseducazione involontaria: la legge degli effetti collaterali involontari nell'educazione. Roma: Armando.

[51] Spranger, E. (2000). Difesa della pedagogia europea. Roma: Armando.

[52] Tagliapietra, A. (2016). Corpo di pazienza. European Journal of Psychoanalysis. Retrieved June 19, 2020, from https://www.journal-psychoanalysis.eu/corpo-di-pazienza/.

[53] Vigani, D. (2017). Is patience a virtue?. Journal of Value Inquiry, 2, 51, 327-340.

[54] Vittadini, G. (2016). Introduzione. In J.J. Heckman, T. Kautz, Formazione e valutazione del capitale umano. L'importanza dei "character skills" nell'apprendimento scolastico (pp. 7-24). Bologna: Il Mulino.

[55] Watts, T.W., Duncan, G.J., \& Quan, H. (2018). Revisiting the Marshmallow Test: A Conceptual Replication Investigating Links Between Early Gratification Delay and Later Outcomes. Psychological Science, 7, 29, 1159-1177.

[56] World Economic Forum (2016), The future of jobs. Employment, Skills and Workforce Strategy for the Fourth Industrial Revolution. Genève: World Economic Forum. Retrieved January 12, 2020, from http://www3.weforum.org/docs/WEF_Future_of_Jobs.pdf.

[57] Wu, A.W., Connors, C. \& Everly, G.S. (2020). COVID-19: Peer Support and Crisis Communication Strategies to Promote Institutional Resilience. Annals of International Medicine. Retrieved June 10, 2020 from https://www.ncbi.nlm.nih.gov/pmc/articles/PMC7146593/. 